\title{
Logística, indicadores socioeconômicos e perdas pós-colheita de hortifrútis em cinco cidades Maranhenses
}

O segmento de hortifrútis ocupa lugar de destaque no agronegócio brasileiro, entretanto enfrenta entraves quanto a perdas pós-colheita. Os estudos sobre esse tema são escassos no Maranhão, especialmente em municípios de pequeno porte. Diante disso, objetivou-se realizar um levantamento socioeconômico e de perdas pós-colheita de hortifrútis no mercado varejista de Afonso Cunha, Codó, Coroatá, Santa Filomena e São Mateus do Maranhão. 0 estudo foi conduzido através de entrevistas diretas em 76 estabelecimentos, através de um questionário composto por perguntas objetivas, relacionadas a aspectos socioeconômicos, manuseio, transporte, armazenamento, comercialização e perdas pós-colheitas de hortifrútis. Conclui-se que a maioria dos comerciantes apresenta baixo conhecimento técnico de produção (89\%), gestão (71\%) e comercialização $(62 \%)$ de hortifrútis. $O$ grau de escolaridade é predominantemente incipiente e apenas $16 \%$ apresentam curso superior. A renda mensal abrange um a dois salários mínimos (66\%). As frutas e hortaliças apresentam procedência predominantemente incipiente e apenas $16 \%$ apresentam curso superior. A renda mensal abrange um a dois salários mínimos $(66 \%)$. As frutas e hortaliças apresentam procedência
externa, majoritariamente da Bahia, Ceará e Piaú $(85 \%)$. Banana e tomate exibem o maior volume ofertado e estão presentes em mais de $90 \%$ dos estabelecimentos visitados. Entre as frutas, $69,23 \%$ apresentam perdas relativas de magnitude média a alta, ao passo que $100 \%$ das hortaliças analisadas estão nesse patamar de perdas. As desordens fisiológicas são os principais agentes causais e englobam amadurecimento precoce, murchamento, enrugamento da epiderme, brotamento e coloração desuniforme. Torna-se evidente a necessidade de capacitação dos comerciantes quanto a aspectos de gerenciamento e boas práticas pós-colheita, de modo que haja melhorias na qualidade dos hortifrútis ofertados, segurança alimentar e desenvolvimento socioeconômico.

Palavras-chave: Capacitação; Comercialização; Desordens fisiológicas; Procedência; Volume ofertado.

\section{Logistic, socioeconomic indicators and horticultural post-harvest losses in five cities of Maranhão, Brazil}

Fruit and vegetable segment occupies a prominent place in the Brazilian agribusiness, however it faces obstacles regarding post-harvest losses. Studies on this topic are scarce in Maranhão, especially in small municipalities. Therefore, the objective of this study was to conduct a socio-economic and post-harvest losses survey of horticulture in the retail market of Afonso Cunha, Codó, Coroatá, Santa Filomena and São Mateus do Maranhão. The study was conducted with direct interviews in 76 establishments, through a questionnaire composed of objectiv questions, related to socioeconomic aspects, handling, transportation, storage, marketing and post-harvest losses of horticulture. It is concluded that most traders have low technical knowledge of production ( $89 \%$ ), management $(71 \%)$ and marketing $(62 \%)$ of fruits and vegetables. The degree of education is predominantly incipient and only $16 \%$ have bachelor's degree. Monthly income covers one to two minimum wages (66\%). Fruits and ve fruits and ves come from abroad, mostly from Bahia, Ceara and Piaui (85\%). Banana and tomato exhibit the largest analyzed are in this level of losses. Physiological disorders are the main causative agents and include early ripening wilting wrinkling of the epidermis, budding and uneven coloring. It becomes evident the need for training of traders regarding management aspects and good post-harvest practices, so that there are improvements in the quality of the horticultural products offered, food security and socioeconomic development.

Keywords: Training; Marketing; Physiological disorders; Origin; Volume offered.

Késsia Tenório Figueirinha (iD)

Universidade Federal do Maranhão, Brasil https://lattes.cnpq.br/3021052082249680 http://orcid.org/0000-0002-7817-9034

kessia ad@hotmail.com

Lusiane de Sousa Ferreira (ib

Universidade Federal do Espírito Santo, Brasi http://lattes.cnpq.br/2873060128693838 http://orcid.org/0000-0001-6625-3965

lusianesf@hotmail.com

Deucleiton Jardim Amorim (iD)

Universidade Estadual de São Paulo, Brasil https://lattes.cnpq.br/3121121800829042 http://orcid.org/0000-0002-6789-0760 deucleitonamorim@hotmail.com

Antônio Gabriel da Costa Ferreira (iD Universidade Federal do Maranhão, Brasil https://lattes.cnpq.br/8950526022963441 http://orcid.org/0000-0003-0931-0120 agcf09@gmail.com

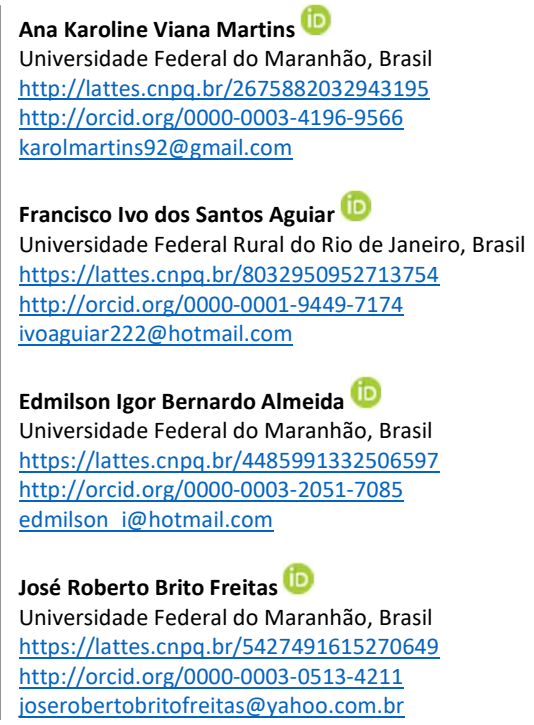

Ricardo Alves de Araújo

Universidade Estadual do Maranhão, Brasil https://lattes.cnpq.br/6876885944020553 http://orcid.org/0000-0001-9696-5680 ricardo zoo@hotmail.com

Leonardo Bernardes Taverny de Oliveira (ib Universidade Federal do Maranhão, Brasil https://lattes.cnpq.br/5822293050229432 http://orcid.org/0000-0002-2971-2066

tavernyzoot@yahoo.com.br
DOI: $10.6008 / C B P C 2179-6858.2021 .005 .0054$
Referencing this:

FIGUEIRINHA, K. T.; FERREIRA, L. S.; AMORIM, D. J.; FERREIRA, A. G. C.; MARTINS, A. K. V.; AGUIAR, F. I. S.; ALMEIDA, E. I. B.; FREITAS, J. R. B.; ARAÚJO, R. A.; OLIVEIRA, L. B. T.. Logística, indicadores socioeconômicos e perdas pós-colheita de hortifrútis em cinco cidades Maranhenses. Revista Ibero Americana de Ciências Ambientais, v.12, n.5, p.698-709, 2021. DOI: http://doi.org/10.6008/CBPC21796858.2021 .005 .0054 


\section{INTRODUÇÃO}

Dentre os principais segmentos do agronegócio, a cadeia produtiva de frutas e hortaliças tem se expandido ao longo dos anos e ocupa lugar de destaque, com reflexos positivos nos indicadores socioeconômicos brasileiros. Atualmente, o Brasil figura numa posição relevante no ranking mundial de produção de frutas. É o terceiro maior produtor, com uma produção estimada em 44 milhões de toneladas, das quais $97 \%$ são direcionadas ao consumo interno e $3 \%$ destinada ao mercado externo (EMBRAPA, 2018).

Um estudo realizado em 2018 pela Confederação da Agricultura e Pecuária do Brasil (CNA), a Associação Brasileira dos Produtores Exportadores de Frutas e Derivados (ABRAFRUTAS) e o Programa Hortifruti Saber \& Saúde, com apoio do Instituto Brasileiro de Horticultura (IBRAHORT), destacou que a fruticultura emprega em torno de 6 milhões de trabalhadores para uma área equivalente a 2,4 milhões de hectares. As hortaliças também têm destaque no agronegócio brasileiro, pois são os produtos que geram maiores lucros por hectare cultivado, em comparação com outras culturas, inclusive os grãos (CLEONICE et al., 2016). No setor hortícola são distribuídos cerca de 7 milhões de empregos para uma área de aproximadamente 2,6 milhões de hectares. Mesmo com o aumento significativo do setor agrícola brasileiro enquadrando o título de uma das mais importantes âncoras da economia, o aumento no índice de perdas pós-colheitas e desperdícios tem se comportado como fatores limitantes na expansão do setor de hortifrútis.

Os estudos mostram que em torno de 30 a $40 \%$ do que é produzido é perdido desde a colheita até a comercialização final, o que representa perdas em nível econômico e social, gerando um desperdício de recursos naturais utilizados na produção, como terra, água, energia e insumos, além do aumento de desigualdades sociais associadas à fome (GUSTAVSSON et al., 2011). Por se tratar de alimentos de alta perecibilidade, a adoção de técnicas incorretas durante o manuseio, acondicionamento, transporte e comercialização, tendem a acelerar suas atividades metabólicas e corroboram para perda da qualidade, o que acarreta aumento do custo de produção e pode tornar a comercialização inviável (SOUSA et al., 2018).

Estudos que englobam as perdas pós-colheita de hortifrútis têm-se mostrado relevantes em vários estados brasileiros, notadamente no Maranhão, devido aos entraves relatados em toda a cadeia produtiva, pelos estudos de Ferreira et al. (2020), Ferreira et al. (2020), Tomm et al. (2018) e Silva et al. (2018). Diante do exposto, objetivou-se realizar um levantamento socioeconômico e de perdas pós-colheita de hortifrútis no mercado varejista de Afonso Cunha, Codó, Coroatá, Santa Filomena e São Mateus do Maranhão.

\section{METODOLOGIA}

O levantamento foi conduzido entre os meses de janeiro a junho de 2019 , nos municípios de

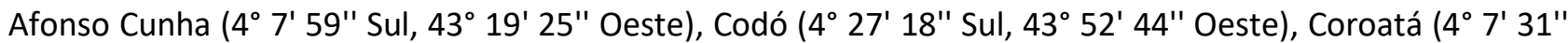

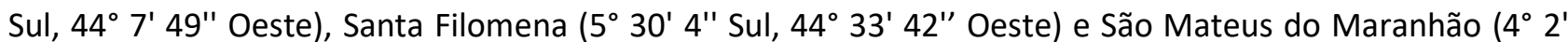
$26^{\prime \prime} \mathrm{Sul}, 44^{\circ} 28^{\prime} 6^{\prime \prime}$ Oeste), os quais compreendem as microrregiões de Coelho Neto, Codó, Alto Mearim e Médio Mearim. Os dados foram coletados através de entrevistas diretas, em pelo menos $50 \%$ dos 
estabelecimentos comerciais de hortifrútis, de cada município, totalizando setenta e seis amostras. As quais abrangeram feiras livres, sacolões e supermercados.

Utilizou-se um questionário elaborado conforme Almeida et al. (2012), composto por perguntas objetivas que abrangeram informações sobre os aspectos socioeconômicos, manuseio, escoamento, acondicionamento, armazenamento, comercialização e perdas pós-colheita de frutas e hortaliças. Tais informações permitiram elaborar um diagnóstico do cenário da comercialização de hortifrútis e perdas póscolheita ocorrentes nos municípios estudados. A renda mensal com a comercialização de hortifrútis foi baseada em termos de salários-mínimos, que na época do estudo era cotado em $\mathrm{R} \$$ 998,00.

A origem das perdas pós-colheita foi tipificada conforme Chitarra et al. (2005) em desordens fisiológicas, danos mecânicos e injúrias fitopatológicas. A perda relativa, em porcentagem, foi estimada pela seguinte fórmula:

$$
\text { Perdas }(\%)=\frac{\mathrm{VO}-\mathrm{VV}}{\mathrm{VO}} \times 100
$$

$\mathrm{Na}$ qual, VO refere-se ao volume ofertado por semana $\left(\mathrm{kg} \mathrm{semana}^{-1}\right)$ e $\mathrm{VV}$ representa ao volume vendido por semana $\left(\mathrm{kg} \mathrm{semana}^{-1}\right)$. Conforme a magnitude, as perdas relativas foram classificadas em perda baixa ( $P R \leq 5,00 \%)$, perda média $(5,01 \leq P R \leq 10,00 \%)$ e perda elevada ( $P R \geq 10,01 \%)$, conforme proposto por Tofanelli et al. (2009). A perda absoluta foi estimada pela multiplicação entre a perda relativa (\%) e o volume médio ofertado da hortaliça, de modo a enfatizar a magnitude do volume perdido em quilogramas por semana (kg semana-1 ${ }^{-1}$. Por sua vez, o volume médio ofertado de cada hortaliça foi obtido pelo quociente entre o seu volume total e o número de estabelecimentos que a ofertava.

Os comerciantes apontaram através de perguntas objetivas, as principais causas primárias de perdas (desordens fisiológicas, danos mecânicos e danos fitopatológicos) para cada hortaliça. Assim, obteve-se a porcentagem média de atuação dessas injúrias sobre a perda relativa total. Nesse sentido, as perdas pós-colheita receberam a denominação de perdas fisiológicas, mecânicas e fitopatológicas, conforme sugerido por Chitarra et al. (2005).

Para melhor detalhamento do estudo, as hortaliças foram ordenadas em hortaliça-fruto, hortaliças subterrâneas e hortaliças folhosas, ao passo que as frutas, em climatéricas e frutos não-climatéricas. Os dados foram analisados por estatística descritiva e apresentados em gráficos e tabelas, conforme o tipo de variável analisada.

\section{RESULTADOS E DISCUSSÃO}

No tocante ao grau de escolaridade, verificou-se que $28 \%$ dos comerciantes concluíram o ensino fundamental; $22 \%$, o ensino médio completo; $16 \%$ possuem formação superior; $15 \%$ não concluíram o ensino fundamental; $9 \%$ não finalizaram o ensino médio, $5 \%$ têm ensino superior incompleto e $5 \%$ são analfabetos (Figura 1). 

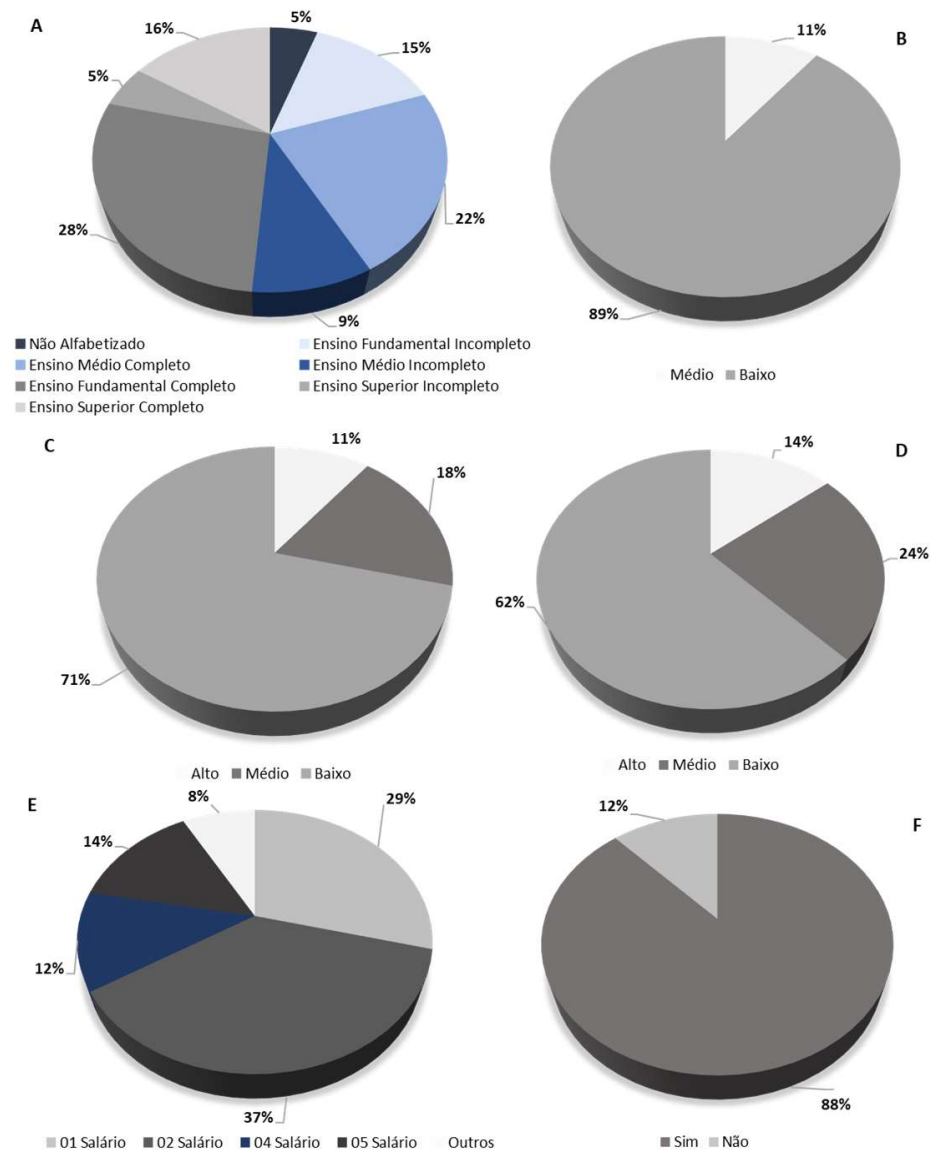

Alto $=$ Médio $=$ Baixo

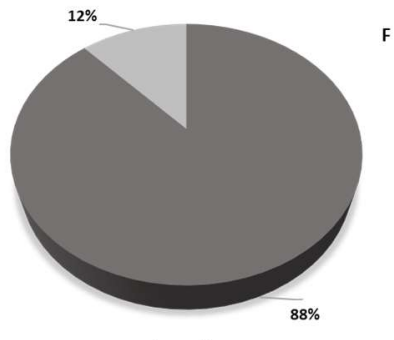

- Sim $=$ Não

Figura 1: Grau de escolaridade (A), Nível de conhecimento técnico em produção (B), Nível de conhecimento técnico em gestão (C), Nível de conhecimento técnico em comercialização (D), Renda mensal (E) e Interesse em capacitação técnica (F) dos comerciantes do setor varejista de hortifrutis de Afonso Cunha, Codó, Coroatá, Santa Filomena e São Mateus (MA).

No que compete aos conhecimentos técnicos de produção, gestão e comercialização, observou-se baixo nível de conhecimento dos comerciantes quanto a tais aspectos, conforme suas próprias indicações. Dos setenta e seis entrevistados, $89 \%$ relatam ter baixo conhecimento acerca da produção dos hortifrutis e apenas $11 \%$ dizem possuir conhecimento mediano quanto a este setor. Fato que pode limitar a percepção quanto a padrões de qualidade, estádio de maturação, sanidade e segurança alimentar dos hortifrútis ofertados, e consequentemente aumentar os riscos de prejuízos na atividade comercial.

Quanto aos conhecimentos técnicos de gestão e comercialização, $71 \%$ e $62 \%$, respectivamente, afirmaram possuir baixo conhecimento, o que pode reduzir ações de marketing, limitações nas escolhas dos preços, gerenciamento da quantidade ofertada, apresentação dos produtos, higiene do ambiente, dentre outros aspectos importantes na gestão e comercialização do setor (Figura 1). E, por consequência, induzir ao aumento de prejuízos resultantes da baixa competitividade e/ou das perdas pós-colheita ocorrentes com os produtos ofertados.

Dados concernentes foram obtidos por Tomm et al. (2018) na microrregião de Chapadinha (MA), onde os autores relataram haver controle inadequado dos aspectos de comercialização e gestão, evidenciando escassez de capacitação em pontos essenciais na elaboração de estratégias que propiciem melhor segurança alimentar, maior qualidade dos produtos ofertados, aumento da vida útil de prateleira, redução de perdas, prejuízos financeiros e impactos ambientais, resultantes dos descartes. A renda média 
mensal obtida através da atividade comercial de hortifrútis, nos cinco municípios, prevaleceu entre um (29\% dos comerciantes) e dois salários-mínimos (37\%). Uma menor parcela dos entrevistados, obtém quatro (12\%), cinco (14\%) e mais que cinco salários-mínimos (8\%) (Figura 1). Isso demonstra a importância do setor para geração de emprego e renda. Constatou-se ainda que os comerciantes com renda mais elevada apresentavam maior grau de escolaridade, conhecimento técnico e infraestrutura.

O interesse de participação em cursos de capacitação em gerenciamento da atividade comercial e boas práticas pós-colheita atingiu $88 \%$ e expressa que embora haja diferenças quanto ao perfil socioeconômico, o mercado varejista de hortifrútis, em sua maioria, apresenta demanda por melhorias, diante do entendimento sobre os entraves e prejuízos ocorrentes no seu cotidiano

No espaço amostral de setenta e seis estabelecimentos comerciais visitados, os sacolões se destacaram como os principais mercados varejistas de hortifrútis (66\%), seguidos pelas feiras livres (29\%) e supermercados (5\%) (Figura 2). Amorim et al. (2018) destacaram que a maior representatividade dos sacolões está atrelada, dentre outros fatores, aos melhores preços praticados, qualidade e diversidade dos hortifrútis comercializados. Foi possível observar que, embora as feiras livres correspondam ao segundo segmento comercial mais representativo, elas não conseguem atender de forma significativa a demanda, tendo em vista a carência na diversidade de produtos ofertados. No que se refere aos supermercados, a menor representatividade pode estar atrelada ao fato de que apenas dois municípios (Codó e Coroatá) dos cinco avaliados, comercializam hortifrútis nesse nicho de mercado, dando prioridade a outros alimentos e itens do varejo.

No Maranhão, um dos grandes entraves na comercialização de frutas e hortaliças diz respeito à procedência, pois cerca de $85 \%$ dos hortifrútis advêm de outros estados, com destaque para o Ceará, Piauí e Bahia. Uma pequena parcela de $8 \%$ e $7 \%$, são oriundos de cidades vizinhas e do próprio município, respectivamente (Figura 2). Esses resultados assemelham com os obtidos por Ferreira et al. (2020), Ferreira et al. (2020), Silva et al. (2018) e Tomm et al. (2018), os quais já haviam reportado a maior parte do que é comercializado em outras vinte cidades maranhenses também advêm de outros estados.

Isso evidencia a necessidade de incentivo do poder público para produção de hortifrútis no Maranhão, que se destaca como um dos maiores estados brasileiros em extensão geográficas e possui condições edafoclimáticas privilegiadas para expansão da fronteira agrícola, conforme destacado por Nascimento et al. (2019).

Os hortifrútis são escoados entre o setor produtivo e o comercial, predominantemente através de caminhões cobertos com lonas, em estradas asfaltadas, porém com condições precárias de conservação rodoviária no perímetro maranhense (Figura 2). Isso pode ser considerado alarmante, conforme as afirmações de Cecctato et al. (2012), os quais salientaram que as frutas e hortaliças caracterizam-se como produtos de elevada perecibilidade e quando submetidos às condições mencionadas no presente estudo, tendem a alterar sua qualidade e consequentemente, reduzir sua vida útil de prateleira. O que culmina em aumento de prejuízos no setor comercial e/ou aumento dos preços praticados para tentar compensar o que foi perdido. 
Fator preponderante para manutenção da qualidade e conservação de determinados tipos de hortifrútis, como as frutas climatéricas, hortaliças-fruto e hortaliças folhosas, o armazenamento (refrigerado e/ou atmosfera modificada) é adotado por apenas $11 \%$ dos comerciantes. Destes, 7 e $4 \%$ fazem uso de acondicionamento em freezer e geladeiras, respectivamente, o que dependendo do tipo de fruta e/ou hortaliça não é recomendado, por exprimir um ambiente seco e frio (Figura 2).
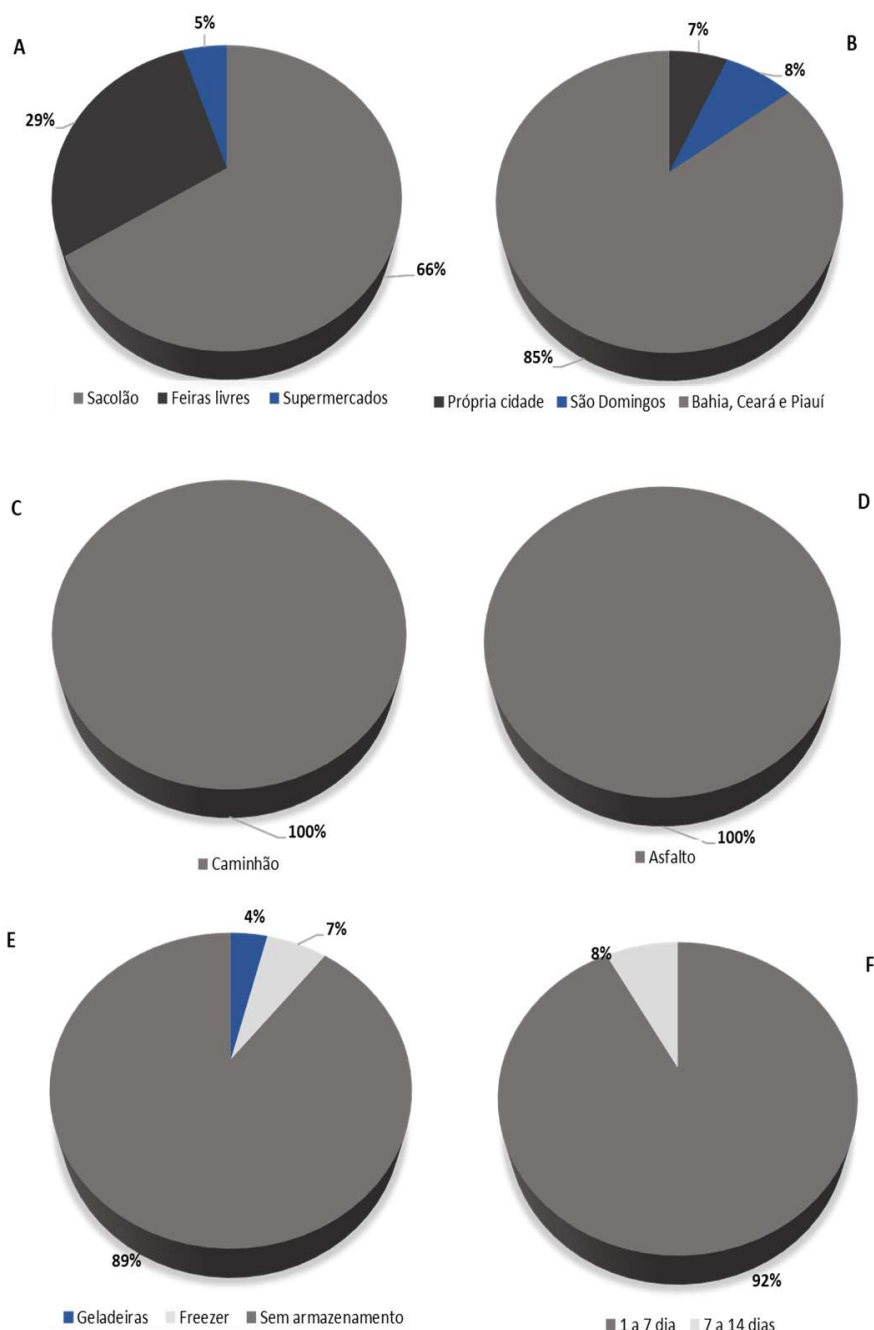

D

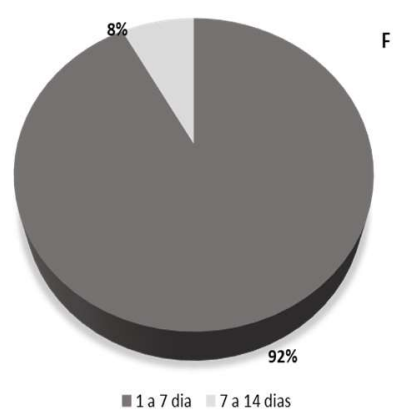

Figura 2: Percentual de estabelecimentos de hortifrutis (A), Origem dos produtos (B), Transporte utilizado (C), Escoamento da produção (D), Armazenamento (E) e Período de estocagem (F) de frutas e hortaliças do setor varejista de Afonso Cunha, Codó, Coroatá, Santa Filomena e São Mateus (MA).

Para Spagnol et al. (2018), a utilização de sistemas refrigerados tem se portado como um dos meios mais eficientes para redução da taxa metabólica dos alimentos e, consequentemente, aumento na vida útil pós-colheita. Nesse aspecto, o seu uso deve ser analisado, principalmente por comerciantes com maior poder aquisitivo. Contudo, outras soluções de menor custo também podem empregadas, como o revestimento de frutos com embalagens plásticas, cuja eficiência foi destacada por Freitas Júnior et al. (2020), Aguiar et al. (2020) e Silva et al. (2020) em pesquisas com goiaba, mamão e tomate comercializados na Ceasa de São Luís (MA), respectivamente.

Quanto ao tempo de estocagem, 92\% dos comerciantes afirmaram que o tempo máximo é de sete dias para os hortifrútis com maiores demandas de consumo. Apenas $9 \%$ conseguem repor o estoque a 
cada 24 horas e $8 \%$ mencionaram que produtos pouco consumidos e mais resistentes à prateleira, permanecem entre 7 a 14 dias (Figura 2). Desta forma cria-se uma alerta quanto ao conhecimento dos comerciantes sobre a sazonalidade desses produtos, pois é provável que embora persistam na prateleira, a sua qualidade é drasticamente reduzida. Soluções plausíveis seriam o planejamento da quantidade ofertada e adoção de preços atraentes ao consumidor, para evitar maiores prejuízos com as perdas.

Quanto ao fluxo de frutas e hortaliças comercializadas nos cinco municípios, banana, maçã, maracujá, mamão, uva, melão, goiaba, manga, abacaxi e abacate compreendem as dez frutas mais comercializadas, estando presentes em mais de 50\% dos estabelecimentos visitados (Figura 3). Dessas, nove frutas estão inseridas no ranking das frutas mais vendidas durante o ano de 2017 (CEAGESP).

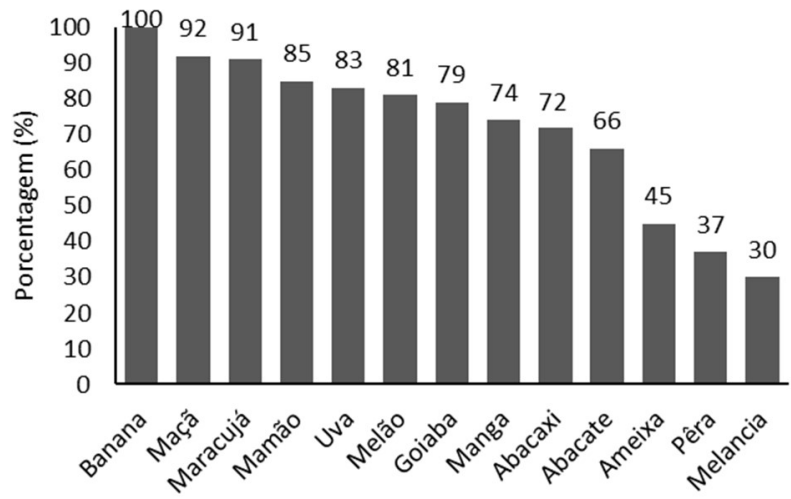

Figura 3: Porcentagem de oferta de frutas comercializadas conforme os estabelecimentos comerciais de Afonso Cunha, Codó, Coroatá, São Mateus e Santa Filomena (MA).

No que compete às hortaliças, as mais comercializadas nos municípios maranhenses estudados, também estão inseridas no levantamento feito pela CEAGESP em 2017. Tomate, pimentão, batata e pepino lideram o ranking dentre as hortaliças mais procurados pelo público consumidor, respectivamente, sendo comercializadas em mais de $92 \%$ dos segmentos comerciais (Figura 4). Atrelado a isso, os comerciantes ressaltam que as frutas e hortaliças mais comercializadas são, consequentemente, aquelas que geram maior lucratividade. A Tabela 1 apresenta estimativas sobre o volume ofertado, perdas pós-colheita e fatores causais de perdas de frutas climatéricas e não-climatéricas.

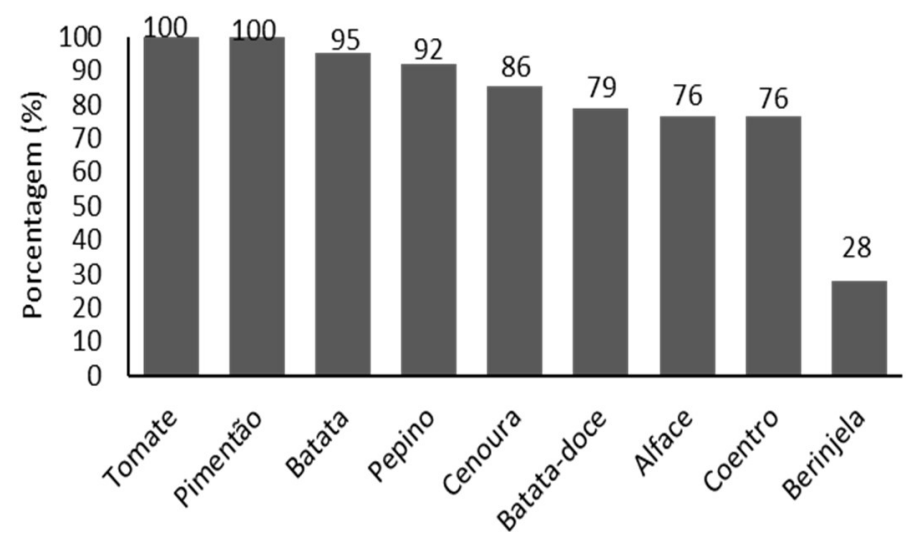

Figura 4: Percentual de oferta de hortaliças comercializadas conforme os estabelecimentos comerciais de Afonso Cunha, Codó, Coroatá, São Mateus e Santa Filomena (MA), 2019. 
Tabela 1: Volume ofertado, perdas relativa, perda absoluta, classe e causas de perdas pós-colheita de frutas no setor varejista de Afonso Cunha, Codó, Coroatá, São Mateus e Santa Filomena (MA).

\begin{tabular}{|c|c|c|c|c|c|c|c|c|}
\hline \multirow{2}{*}{ Grupo } & \multirow{2}{*}{ Frutas } & \multirow{2}{*}{ VMO } & \multirow{2}{*}{ PR \pm e } & \multirow{2}{*}{ PA } & \multirow{2}{*}{ Classe } & \multicolumn{3}{|c|}{ Causa das perdas (\%) } \\
\hline & & & & & & DF & DM & DFP \\
\hline \multirow{11}{*}{ Climatéricas } & Abacate & 50 & $19,20 \pm 1,12$ & 9,23 & Alta & 5,87 & 4,35 & 4,35 \\
\hline & Mamão & 103 & $14,85 \pm 2,61$ & 15,30 & Alta & 6,82 & 5,47 & 2,54 \\
\hline & Manga & 50 & $14,40 \pm 1,18$ & 7,20 & Alta & 6,06 & 3,60 & 4,73 \\
\hline & Ameixa & 79 & $12,65 \pm 1,39$ & 10,00 & Alta & 6,49 & 3,82 & 2,33 \\
\hline & Pêra & 42 & $12,30 \pm 1,10$ & 5,24 & Alta & 6,79 & 5,50 & - \\
\hline & Maracujá & 90 & $8,66 \pm 0,89$ & 7,83 & Média & 4,67 & 2,39 & 1,59 \\
\hline & Goiaba & 61 & $8,00 \pm 0,75$ & 4,91 & Média & 4,00 & 2,42 & 1,57 \\
\hline & Banana & 240 & $6,46 \pm 3,07$ & 15,50 & Média & 3,25 & 3,00 & 0,21 \\
\hline & Melão & 75 & $6,00 \pm 0,76$ & 4,50 & Média & 6,00 & - & - \\
\hline & Maçã & 105 & $4,76 \pm 0,58$ & 4,44 & Baixa & 2,38 & 1,44 & 0,93 \\
\hline & Melancia & 202 & $3,76 \pm 1,23$ & 7,62 & Baixa & 1,88 & 1,18 & 0,69 \\
\hline \multirow{2}{*}{ Não-climatéricas } & Abacaxi & 85 & $6,58 \pm 1,13$ & 5,60 & Média & 2,94 & 1,99 & 1,64 \\
\hline & Uva & 116 & $3,33 \pm 0,78$ & 4,13 & Baixa & 1,57 & 1,09 & 0,65 \\
\hline
\end{tabular}

$\mathrm{VMO}=$ Volume médio ofertado $\left(\mathrm{kg} \mathrm{semana}^{-1}\right) ; \mathrm{PR}=$ Perda relativa $(\%) ; \mathrm{PA}=$ Perda absoluta $\left(\mathrm{kg} \mathrm{semana}^{-1}\right) ; \mathrm{DF}^{2}=$ Desordem fisiológica (\%); DM = Dano mecânico (\%); DFT = Dano fitopatológico (\%).

O volume ofertado oscilou de 42 a $240 \mathrm{~kg} \mathrm{semana}^{-1}$, cuja banana ( $240 \mathrm{~kg}$ semana-1) e melancia (202 $\mathrm{kg} \mathrm{semana}^{-1}$ ) apresentaram os maiores quantitativos. A banana exprimiu volume aproximadamente seis vezes superior ao da pera, o que de acordo com Mankiw (2005) e Bosqueiro (2018) pode estar associado ao hábito de consumo, sabor, aparência, preço e sazonalidade, que consistem em variáveis importantes na curva de demanda de produtos agrícolas.

As perdas para frutas climatéricas foram ordenadas em: abacate $(19,20 \pm 1,12)>$ mamão $(14,85 \pm 2,61)>$ manga $(14,40 \pm 1,18)>$ ameixa $(12,65 \pm 1,39)>$ pera $(12,30 \pm 1,10)>$ maracujá $(8,66 \pm 0,89)>$ goiaba $(8,00 \pm 0,75)>$ banana $(6,46 \pm 3,07)>$ melão $(6,00 \pm 0,76)>$ maçã $(4,76 \pm 0,58)>$ melancia $(3,76 \pm 1,23 \%)$. Ao passo que para não-climatéricas, abacaxi $(6,58 \pm 1,13)>$ uva $(3,33 \pm 0,78 \%)$.

Em torno de $46 \%$ das frutas climatéricas apresentaram perdas altas (PR $\geq 10,01 \%)$ e $64 \%$ delas exibiram perdas relativas superiores às frutas não-climatéricas. Segundo Buzby et al. (2012), isto pode estar relacionado a aspectos de metabolismo pós-colheita, tendo em vista que as frutas climatéricas têm incremento da atividade respiratória e síntese do etileno, quando conservadas em condições similares a relatadas no presente estudo, ou seja, de modo inadequado desde o transporte à comercialização final para maioria dos estabelecimentos visitados.

Nesse aspecto, observou-se que alguns comerciantes não atentam à sazonalidade consumo, o que remete em volumes ofertados maiores que a demanda, culminando em prolongamento do tempo de exposição para venda. Isso atrelado à perecibilidade das frutas climatéricas culminou em ocorrência de $82 \%$ de perdas médias a altas e corroborou com os resultados obtidos por Ferreira et al. (2020), Ferreira et al. (2020) e Silva et al. (2018) em outras dezenove cidades maranhenses. Assim, os resultados apontam que várias cidades maranhenses apresentam indicadores alarmantes de perdas pós-colheita, possivelmente relacionados à baixa capacitação, limitada infraestrutura de serviços e procedência longínqua dos hortifrútis ofertados.

A banana apresentou o maior volume ofertado $\left(240 \mathrm{~kg} \mathrm{semana}^{-1}\right)$ e perda relativa média $(5,01 \leq \mathrm{PR} \leq 10,00 \%)$. Todavia, é importante ressaltar que esta fruta apresentou perda absoluta ( $\left.\mathrm{kg} \mathrm{semana}^{-1}\right)$ 
superior às demais avaliadas, inclusive algumas com perdas relativas maiores, como abacate, mamão, manga, ameixa, pera, maracujá e goiaba. Portanto, o dimensionamento do volume ofertado é muito importante para entender os impactos das perdas sobre a rentabilidade da atividade comercial.

Embora alguns quantitativos de perdas absolutas sejam aparentemente baixos, a soma cumulativa destes valores dentre os diferentes produtos comercializados semanalmente, podem refletir expressivos prejuízos em médio e longo prazo. Somados aos impactos ambientais decorrentes da destinação final equivocada dos resíduos orgânicos, tais como relatadas por Costa Neta et al. (2020) em Teresina (PI).

As desordens fisiológicas foram as principais causas de perdas e consistiram na perda de firmeza, perda de massa fresca, enrugamento da epiderme, murchamento, amadurecimento precoce e/ou desuniforme, com efeitos negativos na qualidade dos produtos. De acordo com Souza et al. (2014), as desordens fisiológicas ocorrem em resposta a mudanças metabólicas nos tecidos vegetais quando submetidos a situações de estresse, que exercem condições incompatíveis com a fisiologia do produto. Mediante a isso, compreende-se que as frutas climatéricas foram mais susceptíveis.

Para algumas frutas climatéricas, como melão, pera e ameixa, as desordens fisiológicas englobaram mais de $50 \%$ da perda relativa, com destaque aos $100 \%$ estimados para atuação deste fator causal sobre o melão. Conforme Morgado (2013), o melão apresenta vida útil curta quando armazenado sob temperatura ambiente, assim é necessário o uso de técnicas, como refrigeração, para melhoria na conservação. Como maioria dos comerciantes apresentam baixo poder aquisitivo, recomenda-se o eficiente gerenciamento do volume ofertado associado a outras boas práticas, no presente estudo.

Para esse estudo, as hortaliças foram classificadas em hortaliças-fruto (berinjela, tomate, pimentão e pepino), subterrâneas (batata-doce, batata e cenoura) e folhosas (alface e coentro), cujo volume ofertado e aspectos de perdas pós-colheita estão registrados na Tabela 2.

Tabela 2: Volume ofertado, perda relativa, perda absoluta, classe e causas de perdas pós-colheita de frutas no setor varejista de Afonso Cunha, Codó, Coroatá, São Mateus e Santa Filomena (MA).

\begin{tabular}{|c|c|c|c|c|c|c|c|c|}
\hline \multirow{2}{*}{ Grupo } & \multirow{2}{*}{ Hortaliças } & \multirow{2}{*}{ VMO } & \multirow{2}{*}{ PR \pm e } & \multirow{2}{*}{ PA } & \multirow{2}{*}{ Classe } & \multicolumn{3}{|c|}{ Causa das perdas (\%) } \\
\hline & & & & & & $\overline{D F}$ & DM & IFP \\
\hline \multirow{4}{*}{ Frutos } & Berinjela & 42 & $26,36 \pm 2,54$ & 11,00 & Alta & 18,03 & 8,32 & - \\
\hline & Tomate & 534 & $21,24 \pm 2,25$ & 113,50 & Alta & 11,73 & 6,14 & 3,35 \\
\hline & Pimentão & 427 & $20,88 \pm 0,95$ & 89,10 & Alta & 10,16 & 3,84 & 6,86 \\
\hline & Pepino & 151 & $7,96 \pm 2,95$ & 12,00 & Média & 5,02 & 2,93 & - \\
\hline \multirow{3}{*}{ Subterrâneas } & Batata-doce & 146 & $21,77 \pm 0,65$ & 31,73 & Alta & 12,03 & 8,02 & 1,71 \\
\hline & Batata & 390 & $19,94 \pm 2,14$ & 77,71 & Alta & 9,97 & 9,18 & 0,79 \\
\hline & Cenoura & 203 & $11,95 \pm 1,65$ & 24,30 & Alta & 5,50 & 4,87 & 1,57 \\
\hline \multirow{2}{*}{ Folhosas } & Alface* & 125 & $9,73 \pm 1,10$ & 12,22 & Média & 9,73 & - & - \\
\hline & Coentro* & 133 & $7,90 \pm 2,49$ & 10,54 & Média & 7,90 & - & - \\
\hline
\end{tabular}

$\mathrm{VMO}=$ Volume médio ofertado $\left(\mathrm{kg} \mathrm{semana}^{-1}\right) ; \mathrm{PR}=$ Perda relativa $(\%) ; \mathrm{PA}=$ Perda absoluta $\left(\mathrm{kg} \mathrm{semana}^{-1}\right) ; \mathrm{DF}=$ Desordem fisiológica (\%); DM = Dano mecânico (\%); DFT = Dano fitopatológico (\%).

O volume ofertado variou de 42 a $534 \mathrm{~kg} \mathrm{semana}^{-1}$. O tomate se destacou como a hortaliça mais ofertada, cujo volume foi aproximadamente treze vezes superior ao da berinjela (Tabela 2). Os resultados corroboram com Ferreira (2019) que listou o tomate entre os vegetais mais consumidos do Brasil e mencionou que a melhoria dos hábitos de consumo da população, atualmente, tem sido preponderante 
para isso.

Similarmente às frutas, as perdas relativas de hortaliças atingiram limite alarmante, no qual $67 \%$ delas apresentaram perda alta, com enfoque aos grupos de hortaliças-fruto e subterrâneas. Para berinjela, tomate, pimentão, batata-doce, as perdas relativas foram maiores a $20 \%$, o que equivale a uma discrepância de até quatro vezes o limite aceitável de perdas $(5,60 \%)$ recomendado por Foscaches et al. (2012) para pequenos municípios. Portanto, um resultado que pode inferir sobre significativos impactos negativos nos indicadores socioeconômicos e ambientais da atividade.

As perdas para hortaliças-frutos compreenderam 7,96 a 26,36\%, as quais foram classificadas como altas para berinjela, tomate e pimentão, e média para o pepino (Tabela 2). Com exceção da berinjela, as demais hortaliças-fruto estão entre as mais comercializadas, perfazendo $95 \%$ dos estabelecimentos visitados (Figura 2). Embora a berinjela apresente-se como a hortaliça com o menor volume comercializado (41 kg semana $\left.{ }^{-1}\right)$, suas perdas relativas foram bastante altas $(26,36 \%)$, o que pode ser explicado pela pequena demanda para consumo e a perecibilidade do fruto. Apenas $28 \%$ dos comerciantes ofertam berinjela, demonstrando a pouca preferência do público consumidor (Figura 4). Portanto, essas perdas tornam-se bastante expressivas, principalmente frente ao volume ofertado e o espaço amostral da pesquisa, tendo em vista que pode ocasionar interferência direta no lucro da atividade comercial.

Por sua vez, tomate e pimentão apresentaram expressivos volumes ofertados (534, 21 e $426,71 \mathrm{~kg}$, respectivamente) e índices de perdas pós-colheita (21,24 e 20,88\%), o que concerne com Tofanelli et al. (2009). Segundo os autores, quanto mais altos os volumes ofertados, maiores são as perdas pós-colheita, atreladas à perecibilidade do produto e práticas pós-colheita inadequadas. Assim, dadas às circunstâncias essas duas hortaliças também se destacaram negativamente quanto à perda absoluta.

As principais causas de perdas foram as desordens fisiológicas, cujos impactos abrangeram até $68 \%$ da perda relativa, como na berinjela. Resultados similares foram obtidos por Tomm et al. (2018) na Microrregião de Chapadinha, os quais relataram precoce amadurecimento, perda de massa fresca, enrugamento da epiderme, perda de firmeza e alterações na coloração em hortaliças-fruto, associado ao mau planejamento do volume ofertado e limitação na adoção de práticas corretas de conservação desde o transporte das hortaliças, que também procediam de regiões distantes.

As perdas relativas de hortaliças subterrâneas variaram de 11,95 a $21,77 \%$ e foram classificadas como altas para todas as hortaliças analisadas. Novamente, as desordens fisiológicas foram as principais causas de perdas pós-colheita, acarretando estimativas de 12,03\% para batata-doce, $11,73 \%$ para batata e $10,16 \%$ para cenoura.

O volume ofertado dessas hortaliças junto ao setor varejista é consideravelmente alto chegando a atingir médias de comercialização semanal de 389,59; 203,19 e 145,78 kg, respectivamente para batata, cenoura e batata-doce, o que tende a resultar em perdas elevadas (Tabela 2). Nesse aspecto, os comerciantes relataram que um dos principais entraves está vinculado ao tempo de exposição na prateleira. E que embora haja uma boa aceitação para consumo, em determinadas épocas do ano, esse tempo de oferta pode aumentar devido à concorrência. 
Isso aumenta a ocorrência de desordens fisiológicas, como o brotamento, perda de massa, perda de firmeza e alteração na cor. Dentre as desordens fisiológicas, o brotamento foi o problema mais pontuado, principalmente no que concerne à batata. Isso corrobora com os resultados encontrados por Sousa et al. (2018) e Tomm et al. (2018) para Microrregião de Chapadinha. Em consonância, os autores salientaram que esse distúrbio ocorre com maior frequência em função do tempo de comercialização e volume ofertado.

Para as hortaliças folhosas, as perdas relativas variaram de 7,90 a 9,73\% e podem ser classificadas como médias. Estas foram ocasionadas em sua totalidade por desordens fisiológicas, relacionadas principalmente ao murchamento. Neste contexto, Figueiredo (2016) ressaltou que alface e coentro são suscetíveis à rápida perda de água após a colheita, assim é recomendado o uso de recobrimentos plásticos, molhamento, mergulhia ou evitar-se a exposição direta à radiação solar, como forma de auxiliar na redução de perdas durante a comercialização.

O presente estudo permitiu uma abordagem mais ampla acerca das técnicas de comercialização e manuseio de frutas e hortaliças, ficando evidente a necessidade na adoção de práticas que viabilizem a oferta desses alimentos. Um melhor planejamento da quantidade ofertada, higienização dos ambientes e bancadas, investimentos em tecnologias de armazenamento, podem contribuir de forma significativa para oferta de alimentos com maior qualidade, propiciar melhor rentabilidade e reduzir impactos ambientais decorrentes da destinação equivocada de resíduos orgânicos.

\section{CONCLUSÕES}

Entre os comerciantes entrevistados, a maioria apresenta baixo conhecimento técnico de produção (89\%), gestão (71\%) e comercialização (62\%) de hortifrútis. O grau de escolaridade é predominantemente baixo e apenas $16 \%$ apresentam curso superior. A renda mensal abrange um a dois salários mínimos (66\%).

As frutas e hortaliças apresentam procedência externa, majoritariamente da Bahia, Ceará e Piauí (85\%). Os produtos são escoados em caminhões de carga coberta com lona, em vias asfaltadas. A banana e tomate são os dois hortifrútis com maior volume ofertado e estão presentes em mais de $90 \%$ dos estabelecimentos visitados. Entre as treze frutas estudadas, 69,23\% apresentam perdas relativas de magnitudes média a alta, ao passo que $100 \%$ das hortaliças analisadas estão nesse patamar. As desordens fisiológicas são os principais agentes causais e englobam amadurecimento precoce, murchamento, enrugamento da epiderme, brotamento e coloração desuniforme.

Torna-se evidente a necessidade de capacitação dos comerciantes quanto a aspectos de gerenciamento e boas práticas pós-colheita, de modo que haja melhorias na qualidade dos hortifrútis ofertados, segurança alimentar e desenvolvimento sustentável.

\section{REFERÊNCIAS}

ABRAFRUTAS. Associação Brasileira dos Produtores e Exportadores de Frutas e Derivados. Relatório Cenário Hortifruti Brasil. 2018.
AGUIAR, F. I. S.; FREITAS JUNIOR, F. G. B. F.; COSTA NETA, C. M.; MACEDO, K. B. C.; ALMEIDA, E. I. B.; NEVES JUNIOR, A. C. V.; ARAUJO, J. R. G.; SILVA, L. R.; OLIVEIRA, L. B. T.; SHIGAKI, F.. Use of Packaging for 'Hawaii' Papaya Conservation, Sold 
at CEASA of São Luís, Maranhão, Brazil. Journal of

Agricultural Studies, v.8, p.384-396, 2020. DOI:

https://doi.org/10.5296/jas.v8i3.16452

ALMEIDA, E. I. B.; RIBEIRO, W. S.; COSTA, L. C.; LUCENA, H. H.; BARBOSA, J. A.. Levantamento de perdas em hortaliças frescas na rede varejista de Areia (PB). Revista Brasileira de Agropecuária Sustentável, v.2, p.53-60, 2012. DOI: https://doi.org/10.21206/rbas.v2i1.58

AMORIM, D.; PIRES, I. C. G.; FERRAO, G. E.; ALMEIDA, E. I. B. Análise da qualidade e do preço de hortaliças comercializadas no mercado varejista de Chapadinha (MA). Agrotrópica, v.29, p.151-156, 2018. DOI: https://doi.org/10.21757/0103-3816.2017v29n2p151-156

BOSQUEIRO, R.. Só 40\% dos brasileiros consomem hortifrútis diariamente. Hortifruti Brasil, v.175, p.5, 2018.

BUZBY, J. C.; HYMAN, J.. Total and per capita value of food loss in the United States. Food Policy, v.37, p.561-570, 2012. DOI: https://doi.org/10.1016/j.foodpol.2012.06.002

CECCATO, C.; BASSO, C.. Avaliação das perdas de frutas, legumes e verduras em supermercado de Santa Maria-RS. Disciplinarum Scientia: Saúde, v.12, p.127137, 2012.

CHITARRA, M. I. F.; CHITARRA, A. B.. Pós-colheita de frutos e hortaliças: fisiologia e manuseio. 2 ed. Lavras: UFLA, 2005.

CLEONICE, C.; RUDOLFO, B. R.; FERNANDO, F. C.. Anuário Brasileiro de Hortaliças. Santa Cruz: Editora Gazzeta, 2016.

CNA. Confederação da Agricultura e Pecuária do Brasil. Perfil tecnológico de produtores de hortaliças e frutas no País, 2018.

COSTA NETA, C. M.; MARTINS, A. K. V.; AMORIM, D. J.; SILVA, M. S.; FERREIRA, L. S.; SILVA. M. D. C.; PIRES, I. C. G.; ALMEIDA, E. I. B.. Perdas pós-colheita e destinação final de frutas em segmentos comerciais de Teresina (PI). Revista Ibero-Americana de Ciências Ambientais, v.11, n.3, p.440453, 2020. DOI: https://doi.org/10.6008/CBPC21796858.2020.003.0034

EMBRAPA. Empresa Brasileira de Pesquisa Agropecuária. Grandes Contribuições para a Agricultura Brasileira, 2018.

FERREIRA, A. G. C.; FERREIRA, L. S.; FREITAS JUNIOR, F. G. B. F.; SANTOS, M. P.; SILVA, M, S.; AGUIAR, F. I. S.; COSTA, T. V.; ALMEIDA, E. I. B.; SOUSA, W. S.; FREITAS, J. B.. Postharvest losses of fruits and vegetables marketed in seven municipalities of the east mesorregion, Maranhão, Brazil. Journal of Agricultural Studies, v.8, p.335-351, 2020. DOI: https://doi.org/10.5296/jas.v8i3.16098

FERREIRA, L. S.; FERREIRA, A. G. C.; AMORIM, D. J.; SILVA, M. S.; SILVA, L. R.; ALMEIDA, E. I. B.; FREITAS, J. R. B.; SOUSA, W. S.; ARAÚJO, R. A.; OLIVEIRA, L. B. T.. Postharvest losses of fruits and vegetables in different microregions of Maranhão, Brazil. Revista Ibero Americana de Ciências Ambientais, v.11, n.5, p.624-637, 2020. DOI: https://doi.org/10.6008/CBPC2179-6858.2020.005.0056

FERREIRA, T. C.. Fatores que afetam o consumo do Solanum lycopersicum L. (tomate): um estudo comparativo entre consumidores do nordeste e sudeste do Brasil. Monografia (Graduação em Engenharia Agronômica) - Universidade Federal do Rio Grande do Norte, Macaíba, 2019.
FIGUEIREDO, P. M.. Pós-colheita de coentro: efeito da temperatura na qualidade e duração da vida útil. Dissertação (Mestrado em Engenharia Alimentar) - Universidade de Lisboa, Lisboa, 2016.

FOSCACHES, C. A. L.; SPROESSER, R. L.; QUEVEDO-SILVA, F.; LIMA FILHO, D. O.. Logística de Frutas, Legumes e Verduras (FLV): um estudo sobre embalagem, armazenamento e transporte em pequenas cidades brasileiras. Informações Econômicas, v.42, p.37-46, 2012.

FREITAS JÚNIOR, F. G. B. F.; SANTOS, M. P.; MOURA, M. S.; DUARTE, L. G.; MACEDO, K. B. C.; SILVA, M. S.; ALMEIDA, E. I. B; NEVES JÚNIOR, A. C. V.; ARAÚJO, J. R. G.. Uso de embalagem plástica e comestível para conservação de goiaba sob diferentes condições de armazenamento. Revista Ibero-Americana de Ciências Ambientais, v.11, 2020. DOI: https://doi.org/10.6008/CBPC2179-6858.2020.004.0039

GUSTAVSSON, J.; CEDERBERG, C.; SONESSON, U.; OTTERDIJK, R.; MEYBECK, A.. Global food losses and food waste: extent, causes and prevention. Food and Agriculture Organization of the United Nations, p.1-38, 2011.

MANKIW, N. G.. Introdução à Economia. São Paulo: Cengage Learning, 2005.

MORGADO, C. M. A.. Conservação pós-colheita de melões inteiros e minimamente processados. Tese (Doutorado) Universidade Estadual Paulista, Jaboticabal, 2013.

NASCIMENTO, S. S.; MENDES, M. S.; SOUSA, A. N. S.; ALMEIDA, E. I. B.; PIRES, I. C. G.. Panorama da comercialização e perdas pós-colheita no setor varejista de frutas frescas, em Chapadinha (MA). Agrotrópica, v.31, p. 159-168, 2019. DOI: https://doi.org/10.21757 / 01033816.2019v31n2p159-168

SILVA, L. R.; ALMEIDA, E. I. B., FERREIRA, L. S.; FIGUEIRINHA K. T.; FERREIRA, A. G. C.; SOUSA. W. S.. Estimativa e causas de perdas pós-colheita de frutas frescas na Microrregião de Chapadinha, Maranhão, Brasil. Revista Agro@mbiente On line, v.12, p.288-299, 2018. DOI: https://doi.org/10.18227/1982-8470ragro.v12i4.5223

SILVA, M. D. C.; COSTA NETA, C. M.; FREITAS, F. G. B. F.; AGUIAR, F. I. S.; NEVES JUNIOR, A. C. C. V.; ALMEIDA, E. I. B.. Atmosfera modificada em tomate, através de embalagens de baixo custo. In: SOUSA, W. S.; ALMEIDA, E. I. B.; MARQUES, J. I; FERRÃO, G. E.. Inovações tecnológicas no campo. In: WORKSHOP EM ENGENHARIA AGRÍCOLA, 1. Anais. Chapadinha: EDUFMA, 2020.

SOUSA, A. N. S.; ALMEIDA, E. I. B.; NASCIMENTO, S. S.; MENDES, M. S.; SOUSA, W. S.; MELO, P. A. F. R.. Perdas póscolheita de hortaliças no mercado varejista de Chapadinha, Maranhão, Brasil. Agrotrópica, v.30, p.53-60, 2018. DOI: https://doi.org/10.21757 / 0103-3816.2018v30n2p127$\underline{134}$

SOUZA, M. H. C.; SILVA, M. V. T.; VASCONCELO, O. C. M.; OLIVEIRA, F. L.; NETO, A. F.. Avaliação Pós-Colheita do Melão Amarelo submetido a Ensaios de Compressão. Revista Verde, v.9, n.4, p.189-194, 2014.

SPAGNOL, W. A.; JUNIOR, V.S.; PEREIRA, E.; FILHO, N. G. Reducing losses in the fruit and vegetable chains by the 
analysis of shelf-life dynamics. Braz. J. Food Technol.,v.21, 2018. DOI: $\underline{\text { https://doi.org/10.1590/1981-6723.07016 }}$

TOFANELLI, M. B. D.; FERNANDES, M. S.; MARTINS FILHO, O. B.; CARRIJO, N. S.. Avaliação das perdas de frutas e hortaliças no mercado varejista de Mineiros - GO: um estudo de caso. Scientia Agrária, v.10, p.331-336, 2009. DOI: http://dx.doi.org/10.5380/rsa.v10i4.14857
TOMM, T. F. R.; ALMEIDA, E. I. B.; FIGUEIRINHA, K. T. FERREIRA, L. S.; AMORIM. D. J.; GONDIM, M. M. S.. Procedência e perdas pós-colheita de hortaliças na microrregião de Chapadinha, Maranhão, Brasil. Revista Agro@mbiente,v.12, p.200-212, 2018. DOI: https://doi.org/10.18227/1982-8470ragro.v12i3.5026

A CBPC - Companhia Brasileira de Produção Científica (CNPJ: 11.221.422/0001-03) detém os direitos materiais desta publicação. Os direitos referem-se à publicação do trabalho em qualquer parte do mundo, incluindo os direitos às renovações, expansões e disseminações da contribuição, bem como outros direitos subsidiários. Todos os trabalhos publicados eletronicamente poderão posteriormente ser publicados em coletâneas impressas sob coordenação da Sustenere Publishing, da Companhia Brasileira de Produção Científica e seus parceiros autorizados. Os (as) autores (as) posteriormente ser publicados em coletâneas impressas sob coordenação da Sustenere Publishing, da Companhia Brasileira de Produção Cientifica e seus parce
preservam os direitos autorais, mas não têm permissão para a publicação da contribuição em outro meio, impresso ou digital, em português ou em tradução. 